\title{
Effects of 13-nle-motilin on the electrical and mechanical activity of the isolated perfused canine stomach and duodenum ${ }^{1}$
}

\author{
W. E. R. GREEN, H. RUPPIN, D. L. WINGATE ${ }^{2}$, W. DOMSCHKE, E. WÜNSCH, \\ L. DEMLING, AND H. D. RITCHIE
}

From the Department of Experimental Surgery and Academic Unit of Gastroenterology, the London Hospital Medical College, London, the Department of Medicine, University of Erlangen-Nurnberg, West Germany, and the Max Planck Institute of Biochemistry, München, West Germany

SUMMARY Synthetic 13-norleucine-motilin (13-nle-motilin), structural and biological analogue of the naturally-occurring duodenal polypeptide, motilin, is known to stimulate antral and duodenal motor activity in vitro, but delays gastric emptying in man. In this study the direct actions of the synthetic polypeptide on myoelectrical activity and intraluminal pressure have been'studied in the isolated vascular-perfused canine stomach and duodenum. 13-nle-motilin increased intraluminal pressure in the pylorus and duodenum, and dose-response analysis showed the duodenum to be twice as sensitive as the pylorus to the polypeptide. Pressure changes in the antrum were small and not dose-related, but, whereas the basic electrical rhythm in the duodenum was not altered, slow wave frequency, rhythm, and propagation in the antrum were disturbed. Electronic analysis of the duodenal spike increase which accompanied pressure rises demonstrated correlations between increases in spikes, intraluminal pressure, and dose. These results show that the direct effect of the polypeptide on adjacent organs may explain the combination of increased motor activity with delayed gastric emptying as a consequence of disturbance in the co-ordination between antrum, pylorus, and duodenum.

Purified motilin isolated from hog small intestine has been demonstrated to stimulate motor activity in both antral and fundic gland area pouches of the conscious dog (Brown et al., 1971), and in the antrum of the isolated perfused canine stomach (Cook et al., 1973). A physiological role for motilin is suggested by a recent immunofluorescent demonstration of cells containing motilin in the intestinal mucosa of man (Polak et al., 1975). In vitro experiments using 13norleucine-motilin (13-nle-motilin)-synthetic analogue of motilin and biologically just as active as the natural polypeptide (Wünsch et al., 1973)-revealed that the sensitivity of rabbit duodenal and jejunal smooth muscle strips even exceeds that of antral circular muscle (Strunz et al., 1975). Interestingly enough, human gastric evacuation is inhibited by 13nle-motilin (Ruppin et al., 1975)-possibly attribu-

\footnotetext{
${ }^{1}$ A preliminary account of this work was given to the Physiological Society in London, November 1975.

'Address for reprint requests: Dr D. L. Wingate, Academic Unit of Gastroenterology, The London Hospital, Whitechapel, London, E1 1BB.

Received for publication 3 February 1976
}

table, at least in part, to different susceptibilities of gastric and duodenal muscles to the polypeptide. Since there appears to be a discrepancy between the effects of 13-nle-motilin in isolated and intact tissues, the present experiments were carried out on the isolated, vascular-perfused canine stomach and duodenum (Green and Hardcastle, 1970) in which mechanical and electrical changes can be directly measured in an isolated system in which propagated electrical activity and the pyloric sphincter is preserved. These studies were designed to elucidate in more detail the relationship between electrical and mechanical activity of gastric and duodenal muscles in response to 13-nle-motilin.

\section{Methods}

\section{ANIMALS}

The stomach and duodenum of eight adult greyhounds were removed under general anaesthesia and maintained at $37^{\circ} \mathrm{C}$ by vascular perfusion with oxygenated blood from the donor animal. The 
operative technique and the experimental apparatus are fully described elsewhere (Green and Hardcastle, 1970: Ritchie and Hardcastle, 1973). Throughout the experiments, lasting about three hours, arterial perfusion flow and pressure were monitored continuously, and the arterial $\mathrm{pO}_{2}, \mathrm{pCO}_{2}, \mathrm{pH}$, and blood glucose measured at frequent intervals.

\section{PHARMACOLOGICAL AGENTS}

After electrical and mechanical activity had been recorded for an adequate basal period, increasing doses of 13-nle-motilin $(40,80,160,320$, and $640 \mathrm{ng})$ -dissolved in $1.0 \mathrm{ml}$ distilled water-were injected over one minute into the arterial supply of the preparation. The effect of each injection of motilin was compared with that of $1.0 \mathrm{ml}$ distilled water alone. In one experiment, higher doses of the polypeptide $(1.28$ and $2.56 \mu \mathrm{g})$ were administered to elicit the maximal motor response of the preparation. In another experiment, after injection of a pilot dose of 13-nle-motilin, to ensure sensitivity of the preparation, $100 \mu \mathrm{g} / \mathrm{h}$ atropine sulphate were given by continuous intra-arterial infusion; 13-nle-motilin was then added in the same way as described above. Approximately two minutes after each administration of the polypeptide, the venous return from the preparation was diverted for two minutes; the blood collected during this period was discarded in order to remove 13-nle-motilin in the venous effluent after passage through the capillary circulation of the preparation.

\section{MECHANICAL ACTIVITY}

Intraluminal pressure was recorded through a triple lumen water-filled non-perfused open-tip tube connected through a transducer and amplifier to an eight-channel Mingograph 81 ink-jet recorder (Elema-Schönander, Stockholm, Sweden). The open tips of the tubes were placed in the distal antrum, pylorus, and duodenal cap (Fig. 1). The position of the tubes as well as zero (atmospheric) pressure were checked and, if necessary, corrected before each injection of motilin.

\section{MYOELECTRICAL ACTIVITY}

Myoelectrical activity was monitored through silversilver chloride electrodes sutured to five sites on the serosal surface of the stomach and duodenum (Ritchie and Hardcastle, 1973) as shown in Fig. 1. In each experiment, four sites were monitored simultaneously through pre-amplifiers connected to AC amplifier stages of the ink-jet recorder. In some experiments, duodenal activity from two adjacent sites at $\mathbf{D}_{3}$ was simultaneously recorded on magnetic tape using a Medilog data tape recorder (Oxford Instrument Co., Oxford, England).

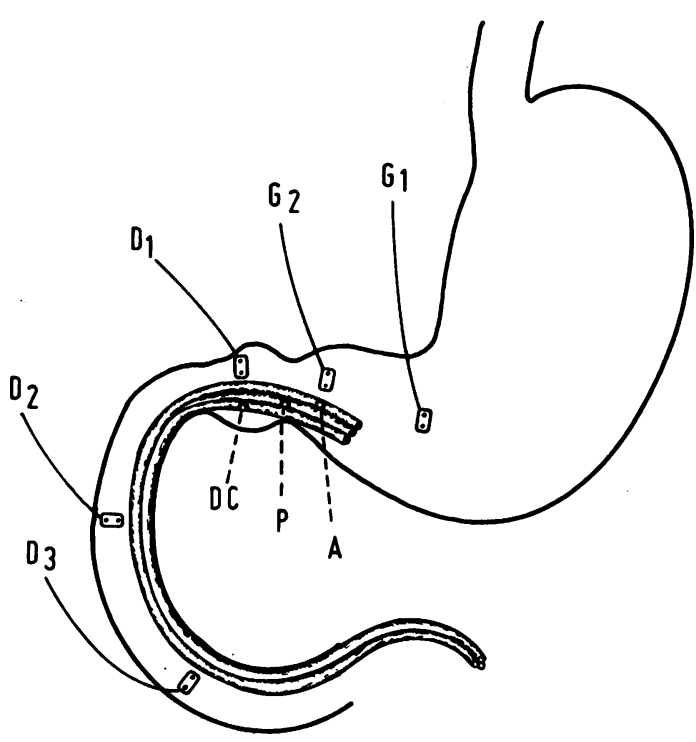

Fig. 1 Position of the electrodes and open-tipped pressure tubes on the isolated canine stomach and duodenum. $G=$ gastric corpus, $D=$ duodenal, $A=$ antrum, $P=$ pylorus, $D C=$ duodenal cap.

\section{DATA ANALYSIS AND STATISTICS}

\section{Intraluminal pressure change}

Mechnical activity was calculated from planimetric measurements (Haff planimeter $315 \mathrm{EF}$, Gebr. Haff, Pfronten, W. Germany) of recorded pressure tracings deviating from zero (atmospheric pressure) line by positive or negative deflections. The planimetric results were expressed as integrated pressure change $\left(\triangle \mathrm{cm} \mathrm{H}_{2} \mathrm{O} / \mathrm{min}\right.$ ) after each injection of 13-nlemotilin. The data were checked by KolmogorovSmirnov's test, and correlation analyses between duodenal, pyloric, and antral pressure changes were performed by using Spearman's rank correlation coefficient $r_{s}$ (Snedecor and Cochran, 1967).

\section{Electrical activity}

Pacesetter potential frequencies were calculated from chart recordings. In addition, in one experiment, the data from tape recordings were analysed in detail to show the incidence of spike activity. The method employed was the recording of myoelectrical activity for exactly five minutes before (A) and five minutes after (B) each motilin injection. The myoelectrical activity from one of the recording sites was used for quantitative analysis. The technique of compressed replay, bandpass filtering, pulse conversion and shaping (Wingate et al., 1975) was used to produce a sequence of pulses corresponding to the spike activity in the duodenal segment as shown in Fig. 2. After 


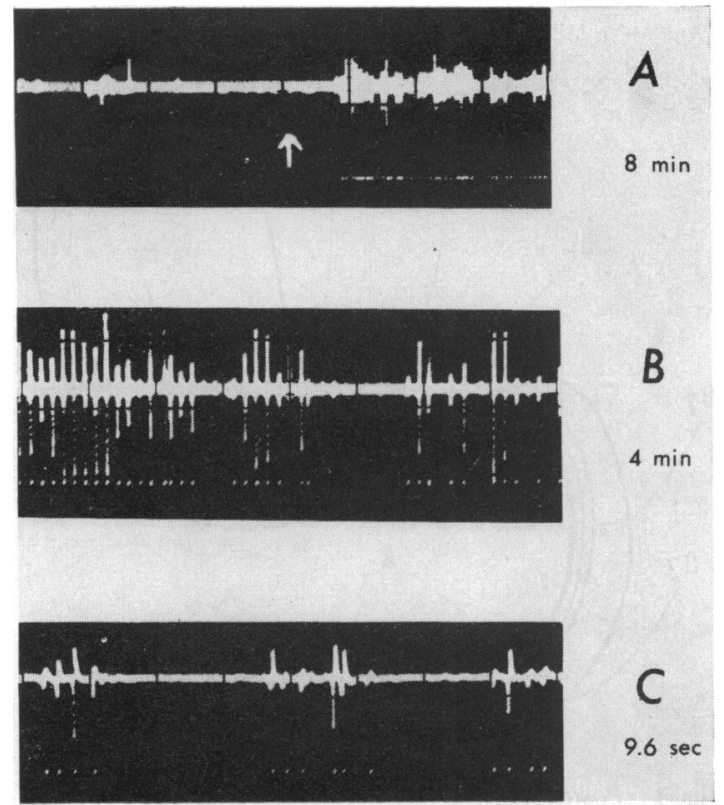

Fig. 2 Electronic conversion of spike activity into digital pulses. In each diagram, the upper trace shows the myoelectric record on tape playback after removal of the slow waves by bandpass filtering. The points on the lower trace show the digital pulses corresponding to the spikes. The recordings were photographed from a twin beam oscilloscope display at different sweep speeds. The periods of time indicate the length of recording shown in each diagram. In A, at low speed, the injection of 13-nlemotilin is indicated by an arrow, and the onset of the spike activity with the corresponding pulses is clearly seen. At a higher sweep speed, in B, spike response following 13-nle-motilin shows the spikes clustered in relation to the basic electrical rhythm. High-speed amplification of two of these clusters in C shows that each cluster is composed of separate spikes, each of which generates a corresponding pulse.

conversion of the recorded spikes into pulses, the data were fed into a Biomac averaging computer (Biomac 1000, Data Laboratories Ltd., Mitcham, Surrey) for the production of spike frequency histograms and interval histograms.

\section{Non-steady state}

In such experiments, the absence of steady-state conditions poses a problem in the analysis of sequential observations. Although there are no significant changes in perfusion pressure and flow, or arterial $\mathrm{pO}_{2}, \mathrm{pCO}_{2}$ and $\mathrm{pH}$ during three hours, there is a steady decline in spontaneous electrical activity (Fig. 3) and in the mechanical (Table 1) and electrical response to stimuli. There is no perfect solution to this problem, which is inherent in ex vivo organ experiments. We have tried to minimize the variation in response due to declining activity in these preparations in two ways. In the calculation of integrated pressure changes (Table 2; Fig. 6) only data from the first hour of perfusion have been used. In the experiment in which duodenal spike activity was electronically analysed, the dose-response effect of 13nle-motilin on spike activity (Fig. 11) was calculated by expressing the increase in spike activity for the five minutes after injection as a percentage of the spike activity during the preceding five minutes on the hypothesis that both spontaneous and evoked spike activity decline with time; this was supported by our observations (Table 3 ; Fig. 3 ).

\section{Results}

\section{MECHANICAL ACTIVITY}

The results are illustrated in Figs. 4-6. There was close correlation $(P<0.005)$ between integrated changes in intraduodenal pressure and intrapyloric pressure (Fig. 4); the relation between them suggests that the increment in pyloric pressure after motilin is approximately doubled in the duodenal lumen. There was also a significant correlation $(P<0.02)$ between integrated change in intrapyloric and antral pressure, while the relationship between integrated pressure change in the lumen of the duodenum and antrum only just achieved statistical significance $(0.025<P<0.05) .13$-nle-motilin caused a rise in intraluminal pressure which was greater in the duodenum and in the pyloric channel (Fig. 5). With increasing doses of the polypeptide, intraluminal pressure rose dose-dependently in the duodenum and pylorus, but by contrast the antral response was not dose dependent (Figs. 5 and 6).

\section{MYOELECTRICAL ACTIVITY}

\section{Pacesetter potentials}

In the stomach, slow waves recurred at a frequency of 4.5 to 5.5 cycles per minute, which is in agreement with the data from other authors (Daniel and Chapman, 1963). 13-nle-motilin caused moderately delayed and irregular action of the gastric pacesetter potentials and-at least for short periods-reversed the direction of the antral slow wave propagation (Fig. 7) apparently by phase-unlocking of the antral pacesetter potentials. In one experiment, reversed propagation was accompanied by visible retroperistalsis of the antrum. The slowing of gastric pacemaker frequency by 13-nle-motilin was not dose related; the reduction of the slow wave frequency ranged from 0.2 to 0.86 cycles per minute (Table 2 ).

13-nle-motilin did not affect either frequency or rhythmicity of the duodenal pacesetter potentials. 


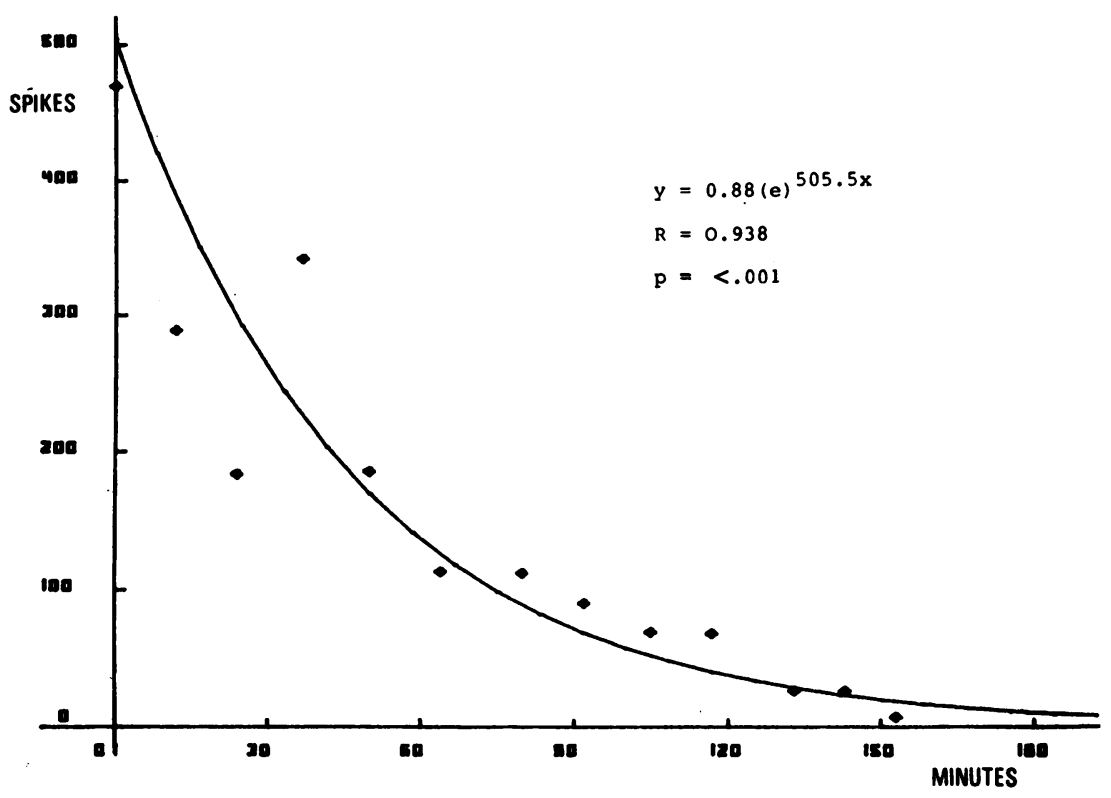

Fig. 3 Decrease of spike activity during $a$ single study. On the horizontal axis, the duration (min) of the study is shown. On the vertical axis are plotted the numbers of spikes during the five minutes preceding each injection of 13-nle-motilin.

\begin{tabular}{|c|c|c|c|c|}
\hline \multirow[t]{2}{*}{$\begin{array}{l}\text { Time } \\
(\text { min) }\end{array}$} & \multirow{2}{*}{$\begin{array}{l}\text { 13-nle- } \\
\text { motilin } \\
\text { (ng-i.a.) }\end{array}$} & \multicolumn{3}{|c|}{$\begin{array}{l}\text { Integrated pressure change } \\
(\triangle \mathrm{cm} \mathrm{H} \mathrm{O} / \mathrm{min})\end{array}$} \\
\hline & & Duodenum & Pylorus & Antrum \\
\hline $\begin{array}{r}0 \\
16 \\
31 \\
47 \\
62 \\
78 \\
93 \\
109 \\
124 \\
140\end{array}$ & $\begin{array}{r}40 \\
640 \\
80 \\
320 \\
160 \\
320 \\
80 \\
640 \\
40 \\
460\end{array}$ & $\begin{array}{r}35 \cdot 0 \\
105 \cdot 5 \\
28 \cdot 0 \\
22.0 \\
13 \cdot 2 \\
21 \cdot 4 \\
10 \cdot 0 \\
34 \cdot 0 \\
12.6 \\
11.0\end{array}$ & $\begin{array}{r}4.0 \\
300.0 \\
15.0 \\
33.0 \\
26.0 \\
71.9 \\
4.0 \\
1.5 \\
-9.4 \\
8.4\end{array}$ & $\begin{array}{r}4.9 \\
12.0 \\
-1.0 \\
27.5 \\
-1.8 \\
-2.8 \\
-2.4 \\
-2.0 \\
-11.4 \\
0.2\end{array}$ \\
\hline
\end{tabular}

Table 1 Integrated pressure changes $\left(\triangle \mathrm{cm} \mathrm{H}_{2} \mathrm{O} /\right.$ min $)$ caused by 13-nle-motilin in relation to the duration of a single study in isolated preparation

\section{Spike analysis}

The automated technique for quantitative spike analysis (Wingate et al., 1975) is a technique which was still undergoing development at the time of these experiments, and there were some initial problems in adapting a method devised for prolonged physiological monitoring to experiments of a different type requiring the analysis of transient responses to repetitive stimuli of an isolated preparation. Because of this, recordings suitable for analysis were not obtained in all preparations. However, the results of one study are presented in some detail since it seems likely that this technique will be valuable in monitoring responses in vivo to agents which modify motor

\begin{tabular}{llllll}
\hline $\begin{array}{l}\text { 13-nle-motilin } \\
\text { (i.a. injection) }\end{array}$ & \multicolumn{5}{l}{ Antral BER frequency change (cycles/min) } \\
\cline { 2 - 6 } & $\begin{array}{l}\text { Exp. } \\
\text { I }\end{array}$ & 2 & 3 & 4 & 5 \\
\hline 40 & -0.8 & $*$ & -0.3 & $*$ & -0.3 \\
80 & -0.1 & -0.6 & -0.5 & $*$ & -0.3 \\
160 & -0.1 & \pm 0 & -0.6 & \pm 0 & -0.2 \\
320 & -0.1 & -0.3 & -0.4 & -0.3 & -0.1 \\
640 & \pm 0 & -0.6 & $*$ & $*$ & $*$
\end{tabular}

Table 2 Change in cycles/min of antral pacemaker frequency after injection of 13-nle-motilin (normal range 4.5-5.5 cycles/min)

* Not recorded.

\begin{tabular}{|c|c|c|}
\hline $\begin{array}{l}\text { Time } \\
(\min )\end{array}$ & $\begin{array}{l}\text { 13-nle-motilin } \\
\text { (ng-i.a.) }\end{array}$ & $\begin{array}{l}\text { Duodenum } \\
\text { increase of electrical } \\
\text { spike activity } \\
(\triangle \text { spikes } / 5 \text { min) }\end{array}$ \\
\hline 0 & 160 & 67 \\
\hline 12 & 80 & 166 \\
\hline 24 & 320 & 159 \\
\hline 37 & 160 & 124 \\
\hline 50 & 240 & 111 \\
\hline 64 & 80 & 14 \\
\hline 80 & 40 & 10 \\
\hline 92 & 320 & 75 \\
\hline 105 & 160 & 38 \\
\hline 117 & 80 & 24 \\
\hline 135 & 240 & 4 \\
\hline 143 & 40 & 5 \\
\hline 153 & 1280 & 37 \\
\hline
\end{tabular}

Table 3 Increase in spike incidence after 13 successive doses of 13-nle-motilin in single isolated preparation 


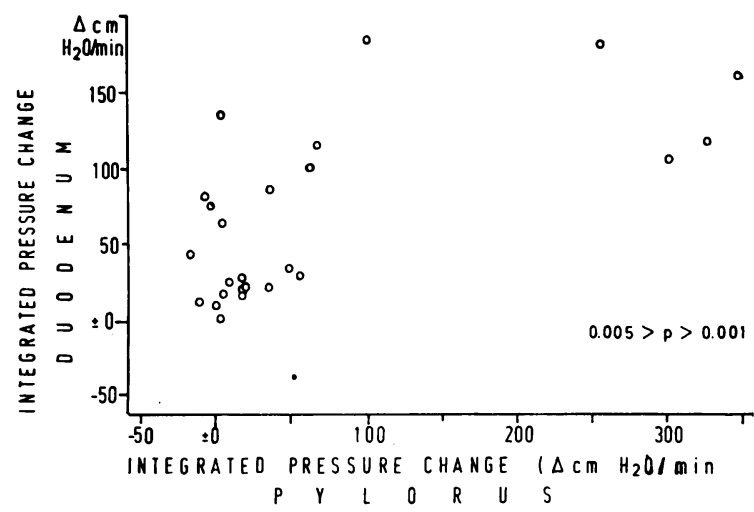

Fig. 4 Relation between duodenal and pyloric sphincter pressure changes after 13-nle-motilin injection.

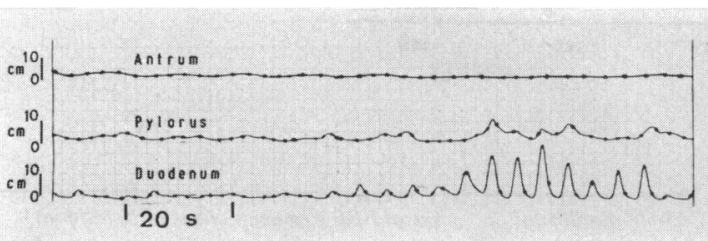

(a)

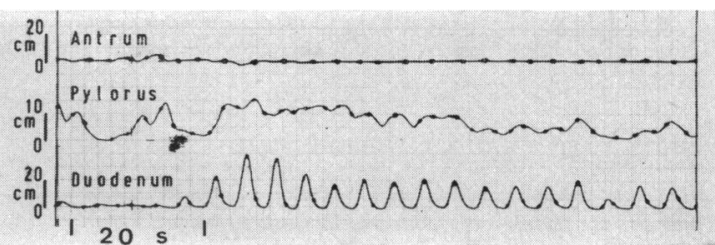

(b)

Fig. 5 Intraluminal pressure change at three sites for two minutes after two different doses of 13-nle-motilin in a single study. (a) Response to $160 \mathrm{ng}$ of the polypeptide given by intra arterial injection. (b) Response to $320 \mathrm{ng}$ of the polypeptide. Note the different scales of pressure recording shown at the left side of the traces.

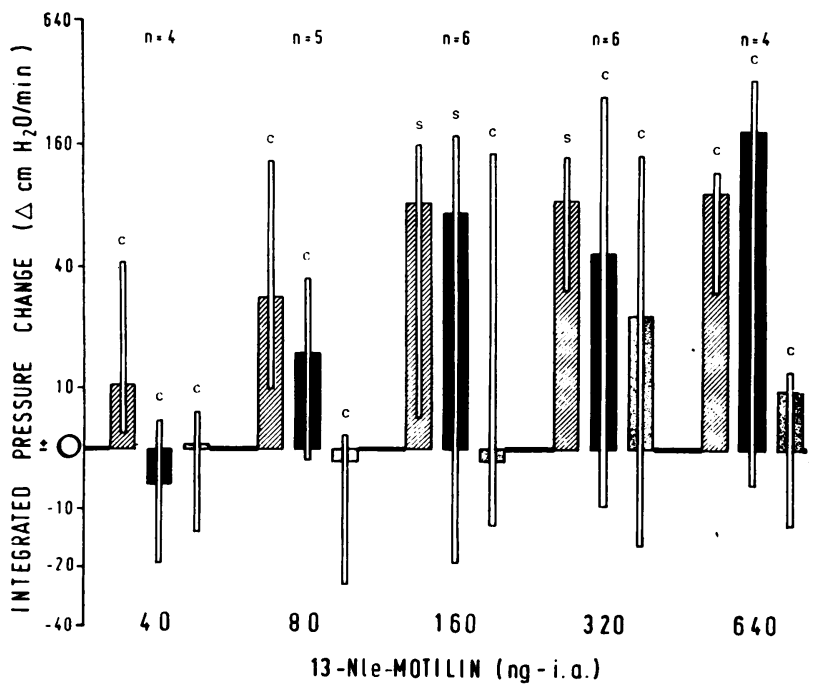

Fig. 6 Intraluminal pressure rises expressed as integrated pressure change $\left(\triangle \mathrm{cm} \mathrm{H}_{2} \mathrm{O} / \mathrm{min}\right.$ ) in antrum, pylorus, and duodenum in response to logarithmically increasing doses of 13-nle-motilin during the first hour of study. The data are given on a logarithmic scale. The broad bars representing mean or median values ( $\square=$ diodenum, $\square=$ pylorus, 圈 $=$ antrum). $95 \%$ confidence limits $(C)$ or standard deviations $(S)$ are indicated by the slender bars. 


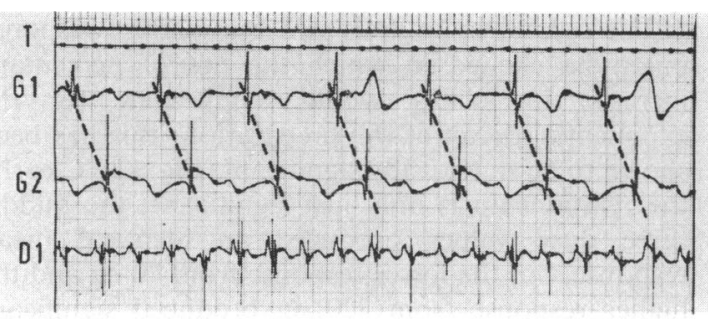

(a)

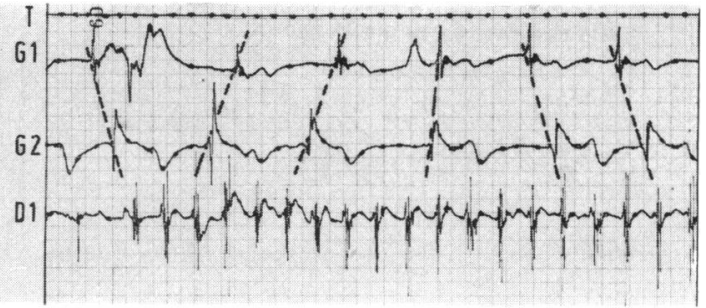

(b)

Fig. 7 Disturbance of gastric pacesetter potential by 13-nle-motilin. (a) Normal antral conduction before 13-nlemotilin. (b) Reversed conduction after 13-nle-motilin.

activity in the stomach and small intestine. In this study, the myoelectric effects of 13 doses of motilin varying between 40 and $1280 \mathrm{ng}$ were recorded on magnetic tape. After conversion into digital pulses, the incidence and temporal distribution of the spikes were studied. A histogram of spike incidence (Fig. 8) suggests that, in spite of the unchanged duodenal pacemaker frequency, the effect of 13-nle-motilin was to increase spike activity. It should be emphasized that all the pulses were derived after the slow waves had been removed by bypass filtering. In order to confirm that the recorded spike activity was of biological origin, and not artefactual, a histogram of the intervals between spikes was constructed on the averaging computer (Fig. 9). This shows a clear peak at 3.4 seconds, which corresponds to a pacesetter frequency of $17.6 / \mathrm{min}$, with regular but diminishing secondary peaks. This frequency was the same as the observed slow wave frequency.

Quantitative spike analysis was accomplished by counting the number of spikes for five minutes before, and five minutes after each dose of 13-nle-motilin, whether expressed in absolute terms or percentage increases, the counts demonstrate the decay in spike activity as the experiment proceeds (Table 3; Fig. 8).

\section{ELECTROMECHANICAL CORRELATION}

The exponential decline in spontaneous spike activity in the preparation poses a problem in analysis. The data in Table 1 show clearly that the pressure changes produced by a given dose of 13-nle-motilin in the latter half of the experiments are smaller than those produced by the same doses administered in the earlier part. The question of whether the spike activity gives an accurate index of motor activity is of some significance in the design of in vivo studies, where monitoring of electrical activity may be possible, but pressure measurement might be difficult. Grivel and Ruckebusch (1972) demonstrated a relationship between spike activity, muscle tension, and intestinal diameter but did not measure intraluminal pressure which is the integral part of several variables. We tested two hypotheses.

The first hypothesis was that there would be a

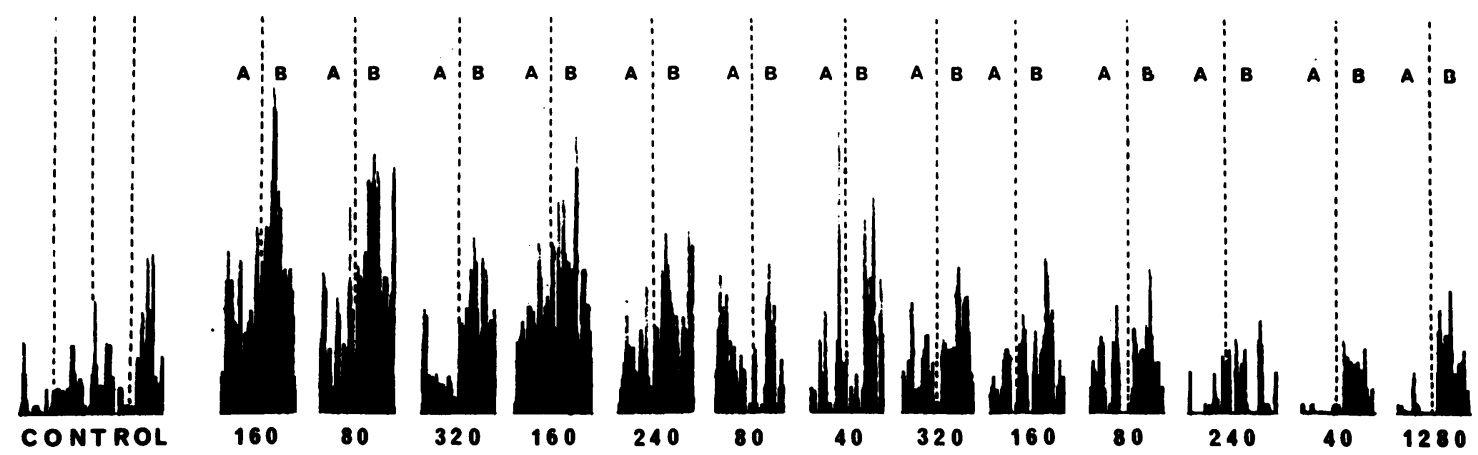

Fig. 8 Spike frequency histogram, with vertical bars showing the incidence of spikes in each half minute for (a) five minutes before and five minutes after (b) 13 successive doses of 13-nle-motilin. The height of each bar is proportional to the number of spikes in 30 seconds. The highest bar (after the first 160 ng 13-nle-motilin dose) represents 1 spike/s, although spikes do not occur at regular intervals, but are clustered as shown in Fig $2 c$. 


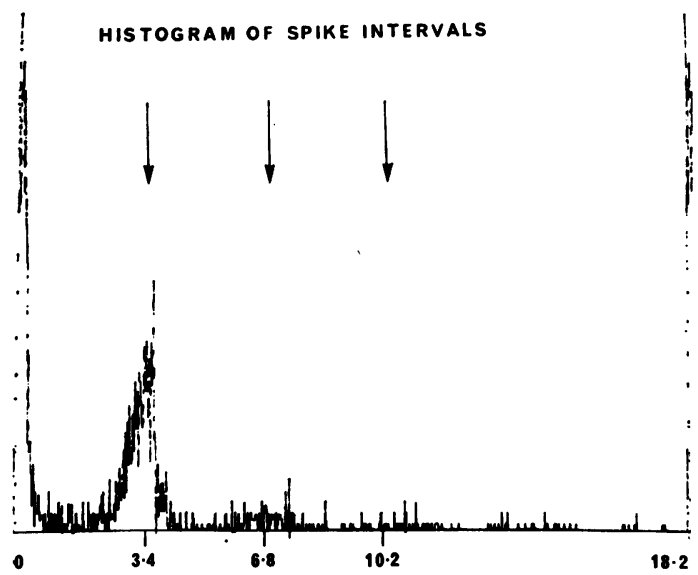

Fig 9. Interval histogram of spike activity in a single study. The interval histogram shows the interval between successive spikes during a single study in which 13 doses of 13-nle-motilin were administered. The arrows show dominant intervals corresponding to a basic electrical rhythm at $17 \cdot 6 / \mathrm{min}$.

relationship between increased spike activity (Table 3) and an increase in integrated intraluminal pressure (Table 1). We found a significant linear relationship $(P<0.005)$, which is shown in Fig. 10. A quantitative relationship of this nature has not been previously reported.

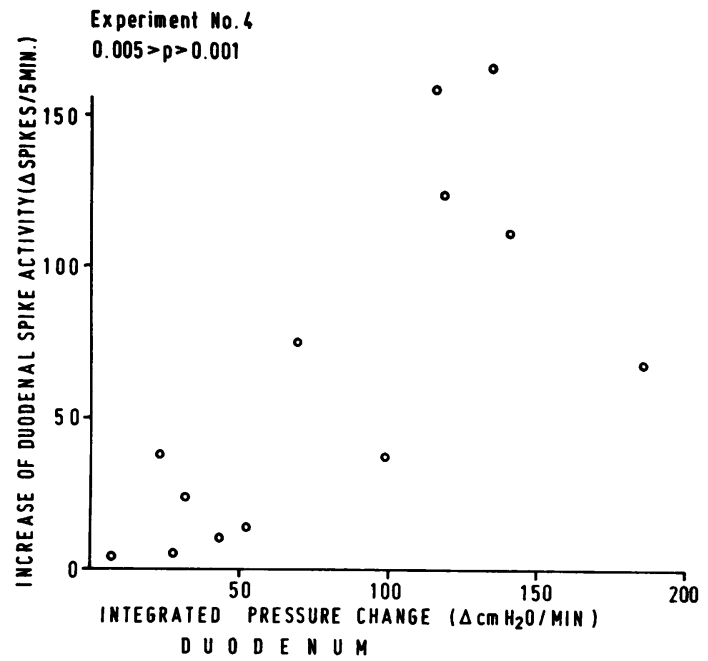

Fig. 10 Relationship between numbers of spikes in response to motilin injection in a single study (vertical axis) and the increase in integrated pressure in the duodenum (horizontal axis) resulting from each injection. The $P$ value shows the statistical significance of the correlation coefficient.
The second hypothesis was that a dose response might be elicited in which the use of percentage increase in spikes would compensate for the exponential decay of the preparation; this has been shown to be statistically significant (Fig. 11). Clearly, the relationship is only just significant; the middle three dose values produced an identical mean response, but the lower response from $40 \mathrm{ng}$ and the higher response from $320 \mathrm{ng}$ produced significant regression. The response to the large dose of $1280 \mathrm{ng}$ (which would greatly increase the statistical significance) has been omitted as it is not closely related to the other data points.

\section{EFFECT OF ATROPINE}

When atropine sulphate $(100 \mu \mathrm{g} / \mathrm{h})$ was given by continuous intra-arterial infusion, neither mechanical nor myoelectrical activity of the preparation could be stimulated by 13-nle-motilin.

\section{Discussion}

Motilin was isolated and purified from hog small intestine by Brown and his colleagues in 1972. The discovery of this polypeptide had been preceded by the observation that duodenal alkalinization stimulated motility-supposedly by duodenal release of a humoral factor-in denervated canine fundic pouches (Brown et al, 1966). Further studies revealed similar gastric motor activity stimulating properties in pancreozymin (Brown, 1967; Brown and Parkes, 1967) and crude secretin (Brown et al., 1971). However, none of these studies included observations on the effect of motilin on duodenal motility. Initially, the principal action of motilin was thought to be stimulation of gastric motor activity; this perhaps explains why Cook et al. (1973), while testing the action of motilin on the isolated, cross-perfused canine stomach, did not mention changes in pyloric and duodenal motor activity. Meanwhile, substantial evidence has shown that motilin-at least in the rabbit and probably also in man-stimulates duodenal rather than gastric motor activity: according to Strunz et al. (1975), the sensitivity of rabbit duodenal and jejunal strips to 13-nle-motilin exceeds that of antral circular muscle by about four times. In man, similarly different susceptibilities of gastric and duodenal muscle to 13-nle-motilin may be responsible for the retardation of gastric emptying by the polypeptide (Ruppin et al., 1975). This may be due to increased duodenal tone resulting in relative obstruction and to uncoordination between the antrum, pylorus, and duodenum. This hypothesis is supported by the results from the present work using synthetic motilin in the isolated homologous-perfused canine stomach and duodenum: after motilin, 


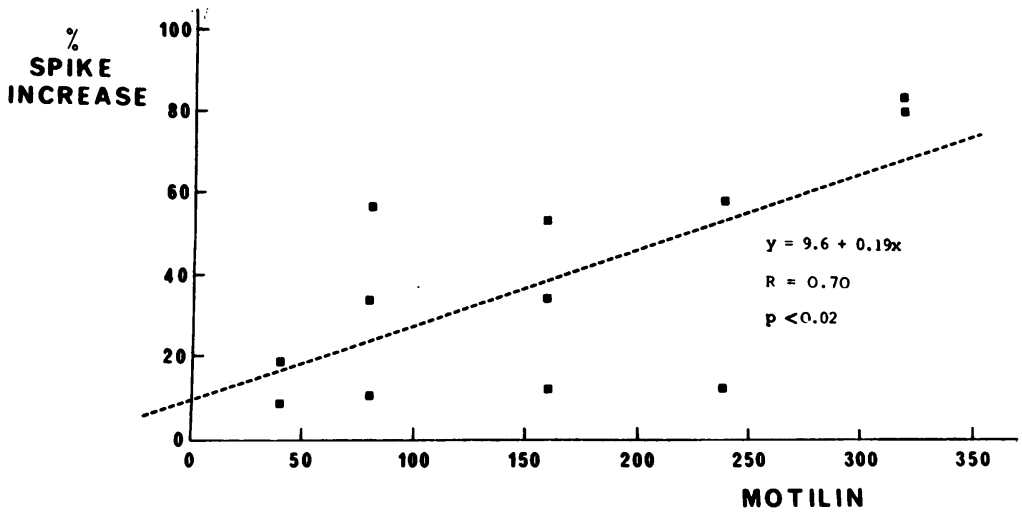

Fig. 11 Relationship between duodenal spike increase and motilin dose. The line shows the calculated regression relationship between percentage increase in duodenal spike activity (vertical axis) after different doses of 13-nle-motilin (horizontal axis) in a single study.

the gastric pacemaker was shown to be disturbed with consecutive irregularity, slowing down, and short-term oral phaseshift of the basal electrical rhythm; this was apparently due to phase-unlocking of antral slow waves.

It has been suggested that phase-unlocking of gastric slow waves causes uncoordinated contractions and altered gastric emptying (Sarna and Daniel, 1975). By contrast, 13-nle-motilin did not interfere with duodenal slow wave activity but even, depending on the dose, enhanced duodenal action potentials. Intraluminal pressure measurements revealed corresponding data: motilin caused a considerable increase in intraduodenal pressure already at a minimal dose of $40 \mathrm{ng}$, whereas the antral pressure was not affected by doses up to $160 \mathrm{ng}$ 13-nle-motilin. Vigorous pyloric contractions were obtained with $80 \mathrm{ng}$ or more of the polypeptide. Thus, the sensitivity of the canine duodenum, pylorus, and antrum to 13-nle-motilin may be expressed as $4: 2: 1$, respectively. This pattern of gastroduodenal motor response to motilin is similar to that caused by the structurally different cholecystokinin in vitro (Fisher et al., 1973), although a recent in vivo study failed to demonstrate actions of CCK on duodenal electrical and mechanical activity in man (Øigaard et al., 1975). In spite of a functional similarity, however, motilin and CCK do not seem to have a similar site of action: while CCK has been reported to contract gastrointestinal muscle stripsat least in part-by the release of acetylcholine (Vizi et al., 1973) a direct action on the smooth muscle cell itself holds true for motilin (Domschke et al., 1974). The reported inhibition on motilin-induced mechanical activity of the isolated perfused stomach by atropine sulphate (Cook et al., 1973) is supported in this study but conflicts with observations on muscle strips (Strunz et al., 1975); in isolated organ preparations, however, atropine effects may not necessarily be pertinent to the mode of action of the given pharmacological agent. Further study of antagonists is clearly indicated.

The variation in sensitivity to 13-nle-motilin between different experiments was considerable, and greater than this preparation usually displays to other stimuli. Since it has been reported that there is a considerable range of fasting plasma motilin levels in man (Bloom et al., 1975), it is perhaps not surprising to find considerable variation in response to identical doses of 13-nle-motilin.

It is of considerable interest that, after 13-nlemotilin, changes in small intestinal intraluminal pressure are correlated with changes in spike frequency. As monitoring of in vivo spike activity may be performed more exactly than intraluminal pressure recording (Øigaard and Dorph, 1974), measurement of spike frequency may prove to be a useful guide to underlying pressure changes in intact animals and man.

We are grateful to Marie-Anne Pilot and Sharon Foweraker for skilled assistance with the experiments. D. L. W. acknowledges support from the Wellcome Trust. We thank Dr Herbert Falk (Freiburg/Brsg.), W. Germany, for the generous provision of facilities.

\section{References}

Bloom, S. R., Ralphs, D. N., Besser, G. M., Hall, R., Coy, D. H., Kastin, A. J., and Schally, A. V. (1975). Effect of somatostatin on motilin levels and gastric emptying. Gut, 16, 834. (Abstract).

Brown, J. C. (1967). Presence of a gastric motor-stimulating property in duodenal extracts. Gastroenterology, 52, 225 229

Brown, J. C., Johnson, L. P., and Magee, D. F. (1966). Effects of duodenal alkalinization on gastric motility. Gastroenterology, 50, 333-339.

Brown, J. C., Cook, M. A., and Dryburgh, J. R (1972). Motilin, a gastric motor activity-stimulating polypeptide: 
final purification, amino-acid composition and C-terminal residues. Gastroenterology, 62, 401-404.

Brown, J. C., and Parkes, C. O. (1967). Effects on fundic pouch motor activity of stimulatory and inhibitory fractions separated from pancreozymin. Gastroenterology, 53, 731-736.

Brown, J. C., Mutt, V., and Dryburgh, J. R. (1971). The further purification of motilin, a gastric motor activity stimulating polypeptide from the mucosa of the small intestine of hogs. Canadian Journal of Physiology, 49, 399405.

Cook, M. A., Kowalewski, K., and Daniel, E. E. (1973). Electrical and mechanical activity recorded from the isolated, perfused canine stomach: the effects of some G.I. polypeptides. Proceedings of the 4th International Symposium on Gastrointestinal Motility, pp. 233-242. Mitchell Press: Vancouver.

Daniel, E. E., and Chapman, K. M. (1963). Electrical activity of the gastrointestinal tract as an indication of mechanical activity. American Journal of Digestive Diseases, 8, 54-102.

Domschke, W., Strunz, U., Mitznegg, P., Ruppin, H., Domschke, S., Schubert, E., Wünsch, E., Jaeger, E., and Demling, L. (1974). 13-Norleucin-Motilin-Analyse der Wirkungen auf den Gastrointestinaltrakt. Naturwissenschaften, 61, 370 .

Fisher, R. S., Lipshutz, W., and Cohen, S. (1973). The hormonal regulation of pyloric sphincter function. Journal of Clinical Investigation, 52, 1289-1296.

Green, W. E. R., and Hardcastle, J. D. (1971). The myoelectrical activity of the isolated perfused canine stomach. Journal of Physiology, 222, 41.

Grivel, M.-L., and Ruckebusch, Y. (1972). The propagation of segmental contractions along the small intestine. Journal of Physiology, 227, 611-625.

Øigaard, A., and Dorph, S. (1974). Quantitative analysis of motility recordings in the human small intestine. American Journal of Digestive Diseases, 19, 804-810.

Øigaard, A., Dorph, S., Christensen, K. C., and Christiansen,
L. (1975). The effect of cholecystokinin on electrical spike potentials and intraluminal pressure variations in the human small intestine. Scandinavian Journal of Gastroenterology, 10, 257-262.

Polak, J. M., Pearse, A. G. E., and Heath, C. M. (1975). Complete identification of endocrine cells in the gastrointestinal tract using semithin-thin sections to identify motilin cells in human and animal intestine. Gut, 16, 225229.

Ritchie, H. D., and Hardcastle, J. D. (eds) (1973). Isolated Organ Perfusion. Crosby Lockwood Staples: London.

Ruppin, H., Domschke, S., Domschke, W., Wünsch, E., Jaeger, E., and Demling, L. (1975). Effects of 13-nlemotilin in man-inhibition of gastric evacuation and stimulation of pepsin secretion. Scandinavian Journal of Gastroenterology, 10, 199-202.

Sarna, S. K., and Daniel, E. E. (1975). Vagal control of gastric electrical control activity and motility. Gastroenterology, 168, 301-308.

Snedecor, G. L., and Cochran, W. G. (1967). Statistical Methods, 6th edn. Iowa State University Press: Ames, Iowa.

Strunz, U., Domschke, W., Mitznegg, P., Domschke, S., Schubert, E., Wünsch, E., Jaeger, E., and Demling, L. (1975). Analysis of the motor effects of 13-norleucine motilin on the rabbit, guinea pig, rat and human alimentary tract in vitro. Gastroenterology, 68, 1485-1491.

Vizi, S. E., Bertaccini, G., Impicciatore, M., and Knoll, J (1973). Evidence that acetylcholine released by gastrin and related polypeptides contributes to their effect on gastrointestinal motility. Gastroenterology, 64, 268-277.

Wingate, D. L., Barnett, T. G., and Green, W. E. R. (1975). High speed-analysis of gastrointestinal myoelectrical activity. Mayo Clinic Proceedings, 50, 529.

Wünsch, E., Brown, J. C., Deimer, K. H., Drees, F., Jaeger, E. Musiol, J., Scharf, R., Stocker, H., Thamm, P., and Wendlberger, G. (1973). Zur Synthese von Norleucin-13Motilin. Zeitschrift fur Naturforschung, 28, 235-240. 